This document is the accepted manuscript version of the following article:

Jebali, S., Airoudj, A., Ferreira, I., Hegemann, D., Roucoules, V., \& Ga11, F. B. L. (2021). Unique combination of spatial and temporal control of maleic anhydride plasma polymerization. Plasma Processes and Polymers. https://doi.org/10.1002/ppap.202000244

$1 \quad$ ((https://doi.org/10.1002/ppap.202000244))

Article type: Full paper

\title{
Unique combination of spatial and temporal control of maleic anhydride plasma polymerization
}

Syrine Jebali ${ }^{1,2}$, Aissam Airoudj ${ }^{1}$, Isabelle Ferreira ${ }^{2}$, Dirk Hegemann ${ }^{3}$, Vincent Roucoules ${ }^{1}$, Florence Bally-Le Gall ${ }^{1 *}$

\footnotetext{
${ }^{1}$ Université de Haute-Alsace, Université de Strasbourg, CNRS, IS2M UMR 7361, F-68100 Mulhouse, France

${ }^{2}$ Institut Français du Textile et de l'Habillement (IFTH), F-68100 Mulhouse, France

${ }^{3}$ Empa, Swiss Federal Laboratories for Materials Science and Technology, Advanced Fibers, Lerchenfeldstrasse 5, 9014 St. Gallen, Switzerland

*Correspondence
}

Dr. F. Bally-Le Gall, Université de Haute-Alsace, Université de Strasbourg, CNRS, IS2M UMR 7361, F-68100 Mulhouse, France

E-mail: florence.bally-le-gall@uha.fr

The chemical properties of plasma polymers strongly depend on the operating conditions of plasma polymerization and impact their final application. Low-pressure pulsed plasma polymerization of maleic anhydride was investigated at different positions from the glow discharge in a unique $1 \mathrm{~m}$ long reactor. Based on a macroscopic approach, the growth kinetics of maleic anhydride plasma polymerization were investigated and led to the identification of three growth regimes. The calculation of apparent activation energies associated with each regime and each position, the chemical characterization of polymer films by XPS and ATR FTIR as well as OES analyses of plasma species formed during deposition strongly indicate a combined spatial and temporal influence on the plasma polymerization kinetics.

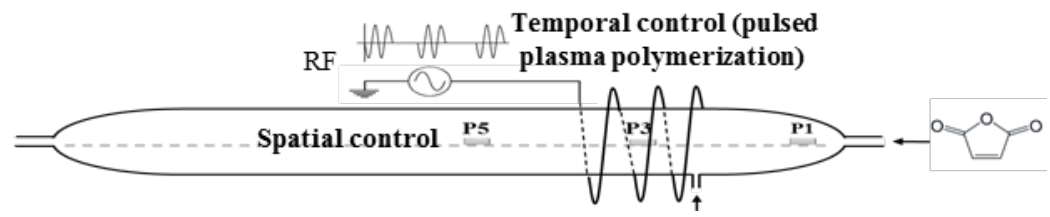




\section{$1 \quad$ Introduction}

34 During plasma polymerization, film growth is ensured by gas phase dissociation processes and surface growth processes under continuous reactivation and recombination reactions. ${ }^{[1]}$ Firstly, Yasuda proposed a growth mechanism known as rapid step-growth polymerization (RSGP). ${ }^{[2]}$ According to this mechanism, free radicals are the most concentrated species and therefore the most likely to react. They can be easily generated by electron impact- excitations or collisional energy transfers. Meanwhile, the deposited film undergoes interactions with the reactive species which may lead to film degradation. The identification of these basic processes at the origin of the crosslinked structure of plasma polymers led to the introduction of the CAP mechanism (Competitive Ablation and Polymerization). ${ }^{[3]}$ Ablation mainly depends on the power provided

to the monomer and its residence time in the plasma. In order to estimate the energy transferred to the gas, Yasuda introduced the reaction parameter $\mathrm{W} / \mathrm{FM}$ where $\mathrm{W}$ is the power provided to the precursor (denoted also as 'monomer' in the following), $\mathrm{F}$ its flow rate, and $\mathrm{M}$ its molecular weight. ${ }^{[4]}$ Thus, at low energy input (energy-deficient regime) linear increase of the mass deposition rate is ensured by the large domination of the polymerization while etching phenomena are absent. ${ }^{[5]}$ At high energy input (monomer-deficient regime), on the contrary, ablation mechanisms are no longer negligible and therefore a decrease in the polymer growth rate can be observed. Thus, the reaction parameter W/F (or W/FM) corresponds to a specific energy that governs reactions within the plasma active zone according to the concept of chemical quasi-equilibrium. ${ }^{[6]}$ This macroscopic approach allows a less complex and more accessible description of plasma polymerization than molecular studies. In fact, for radicaldominated plasma polymerization, the film deposition rate solely depends on the energy provided per particle of the gas mixture flowing through the plasma phase. ${ }^{[7]}$ Taking into account geometrical parameters of the reactor, this macroscopic approach has been further developed by Hegemann et al. and led to the correlation of the polymer film deposition rate 
with an apparent activation energy associated to a specific state of the precursor, related to dissociation energies or enthalpies of formation. ${ }^{[6,8,9]}$ While radical-dominated polymerization mechanism were assumed in numerous studies dealing with plasma polymerization, ${ }^{[10-13]}$ because of the strong presence of radicals within the plasma polymer, ${ }^{[14]}$ other studies have been focused on the importance of ions contribution ${ }^{[15,16]}$. However, these mechanistic studies are still controversial. Many questions are also still open on the location of chain initiation and/or growth, on the substrate or in the plasma phase. ${ }^{[17,18]}$ All these discussions and studies concerning the mechanisms of plasma polymerization including radical polymerization, ionic polymerization, ion-molecule reactions and even fragmentation- poly-recombination of the precursor are well reported in Friedrich's review ${ }^{[14]}$ and frequently debated. ${ }^{[19,20]}$ Despite of these controversial discussions, various authors have agreed on the fact that the polymerization mechanisms can be significantly modified by changing the operating mode of plasma polymerization from continuous to pulsed. ${ }^{[21-25]}$ Pulsed plasma polymerization is characterized by the duty cycle $(D C)$, defined as $t_{\text {on }} /\left(t_{\text {on }}+t_{\text {off }}\right)$, $t_{\text {on }}$ being the time when the radio frequency excitation is supplied to the electrodes and $t_{\text {off }}$, the time during which it is interrupted. A low duty cycle promotes the retention of chemical functions because it limits the fragmentation of the precursor to short time periods. In this way, a temporal control of plasma polymerization is addressed. ${ }^{[23,24]}$ In addition, the influence of the position of the sample in the reactor and more precisely in relation to the discharge on the plasma polymer properties was addressed in several studies. ${ }^{[26-29]}$ Carrying out plasma polymerization in the post-discharge zone (also known as remote plasma deposition) is known to limit the crosslinking of plasma polymers since less ions are found far from the glow discharge, thus leading to a spatial control of plasma polymerization. ${ }^{[30]}$

In this study, the possibility to combine a spatial with a temporal control of plasma polymerization was investigated by performing pulsed plasma polymerization in an original 
home-built low-pressure plasma reactor, being $1 \mathrm{~m}$ long and enabling the deposition of plasma polymers within or outside the glow discharge. For this purpose, maleic anhydride has been chosen as a precursor since it is very sensitive to the operating conditions in which plasma polymerization is performed ${ }^{[23,24,31,32]}$ and it is also a good candidate to fabricate functional polymer thin films for various applications. maleic anhydride plasma polymers have, for instance, been used to control the interactions between cells/bacteria with a surface, ${ }^{[33]}$ to get hydrophilic textiles, ${ }^{[34]}$ to serve as a matrix for the synthesis of nanoparticles ${ }^{[35]}$ or simply to be an efficient ground layer for subsequent post-modification, especially by vapor phase aminolysis reactions mainly to control adhesion properties. ${ }^{[36-38]}$ For these applications, preserving reactive anhydride groups is crucial but challenging. Even at relatively low input energies, anhydride groups can be easily fragmented, compromising the final use of the polymer thin film. A macroscopic approach has been chosen in this work to describe the growth kinetics of pulsed plasma polymerization at different locations in the reactor in order to determine the different activation energies involved during deposition. Chemical characterization of maleic anhydride plasma polymer thin films but also of the plasma phase provided interesting results to get more insights into plasma polymerization kinetics, considering polymerization at various specific energies in three different regions of the plasma reactor (pre-discharge, discharge and post-discharge zones).

\section{EXPERIMENTAL SECTION}

\subsection{Deposition of maleic anhydride plasma polymer by plasma polymerization}

Maleic anhydride, $\mathrm{C}_{2} \mathrm{H}_{2}(\mathrm{CO})_{2} \mathrm{O}$, (Prolabo, $99.5 \%$ purity) was ground into a fine powder and loaded into a stoppered glass gas delivery tube. Then, a degassing step led to vacuum in the tube by performing three freeze-pump-thaw cycles. Maleic anhydride plasma polymer were deposited onto $1 \times 1 \mathrm{~cm}^{2}$ single side-polished silicon wafers (100, Si-Mat), which were cleaned 
107 with ethanol and acetone before use. Plasma polymerization experiments were carried out in a

108 unique, home-built RF plasma reactor, operating at low pressure. The chamber consists of a 109 quartz tube (100 $\mathrm{cm}$ in length and $6 \mathrm{~cm}$ in diameter) coupled with an externally wound copper 110 coil. A pirani pressure gauge in series with a two-stage rotary pump (Edwards E2M 18) 111 connected to a liquid nitrogen cold trap completes the reactor. All parts of the equipment are 112 assembled with grease-free Cajon fittings. An L-C matching network (Dressler, VM 1500W113 ICP) is used to balance the impedances of the generator (Dressler, Cesar 133, $13.56 \mathrm{MHz}$ ) and 114 the reactor by minimizing the standing wave ratio of the transmitted power. Using an 115 oscilloscope, the shape of the pulses during deposition was controlled and the average power $116 \mathrm{~W}$ delivered to the system was calculated according to Equation 1, where $\mathrm{P}_{\mathrm{g}}$ is the continuous 117 wave power input indicated by the generator, $\mathrm{DC}$ the duty cycle, $\mathrm{t}_{\text {on }}$ the pulse-on time, and $\mathrm{t}_{\text {off }}$ 118 the pulse-off time:

$$
W=P_{g} \times D C=P_{g} \times\left[t_{\text {on }} /\left(t_{\text {on }}+t_{\text {off }}\right)\right]
$$

120 Prior to each plasma deposition, the reactor was cleaned for a minimum of 30 min using a high121 power air plasma treatment $\left(\mathrm{P}_{\mathrm{g}}=65 \mathrm{~W}\right)$ to ensure the elimination of residues in the reactor. The 122 substrates were afterwards introduced into the chamber by placing them onto a glass support in 123 the desired zone of the reactor. Three preferential positions were chosen for this study (Figure 124 1): $\mathrm{P} 1$ in the pre-discharge zone, $\mathrm{P} 3$ in the discharge zone, which is located at the middle of the 125 copper coil, and P5 in the post-discharge zone. Position P1 was selected in order to get 126 information at the entrance of the reactor corresponding to the pre-discharge zone. Here, only 127 one position is enough to probe the entire pre-discharge zone. At the opposite, in order to get 128 information in the entire post-discharge zone of the plasma reactor, 6 positions have been well 129 selected, from position P5 to position P10. P5 is located at $45 \mathrm{~cm}$ from the monomer entrance 130 of the reactor, $\mathrm{P} 6$ at $57 \mathrm{~cm}, \mathrm{P} 7$ at $67 \mathrm{~cm}, \mathrm{P} 8$ at $77 \mathrm{~cm}, \mathrm{P} 9$ at $87 \mathrm{~cm}$ and $\mathrm{P} 10$ at $97 \mathrm{~cm}$. For the 131 discharge zone, other positions such as P2 and P4 have also been studied and confirmed the 
same trends as those obtained at P3. Something very important to underline here was the

133 heterogeneity of the coatings according to the location of the samples. All the coatings obtained

134 in position P5 (and for all the above positions: P1, P2, P3, P4) were uniformed (in thickness

135 and chemistry point of view). However, all the coatings obtained beyond position P5 (i.e., at

136 P6, P7, P8, P9 and P10) were non-uniformed. They are composed mainly of particles and

137 heterogeneous layers and could not be used in this study. Therefore, P5 could be considered as

138 a spatial border: All the positions above P5 (and including P5) allowed the deposition of

139 uniform coatings, which were the conditions required for this study.

140 Once a base pressure of approx. $4 \times 10^{-4}$ mbar was reached, the precursor was introduced into

141 the reaction chamber at a constant pressure of 0.1 mbar (which corresponds to a flow rate of

142 approx. $56 \mu \mathrm{g} . \mathrm{s}^{-1}$, corresponding to $0.77 \mathrm{sccm}$ for maleic anhydride). At this stage, the plasma

143 was ignited at different conditions of power input $\left(\mathrm{P}_{\mathrm{g}}=[20-50 \mathrm{~W}]\right)$ while varying the duty cycle

$144(\mathrm{DC}=[2-50 \%])$. The frequency of plasma pulses was kept constant at $816 \mathrm{~Hz}$. Upon completion

145 of deposition, the RF generator was switched off. Prior to venting to atmospheric pressure and

146 retrieving the samples, the monomer feed was kept to flow for $2 \mathrm{~min}$. This step enables the

147 latest created plasma species and living radicals to react and avoids undesirable reaction of

148 residual free radicals with air to take place within the plasma polymer film when the reactor is

149 vented. More details on the experimental setup and experimental conditions are given in Figure

150 S1, Figure S2 and Table S1 in Supporting Information.

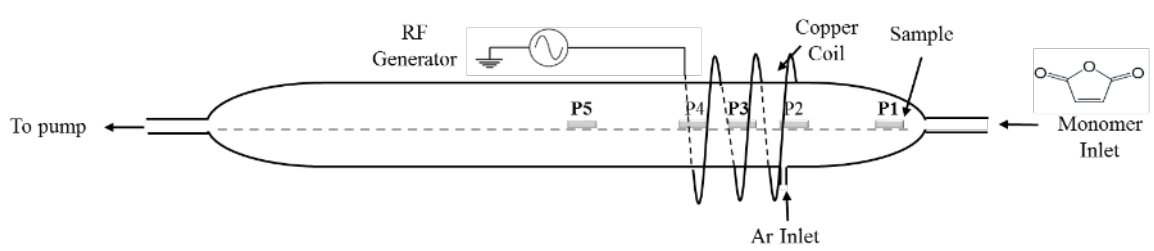

152 Figure 1: Schematic illustration of the low-pressure plasma reactor used for this study. The

153 different studied positions of the sample are indicated (P1 to P5). 
ATR FTIR spectroscopy was used to analyze the chemical composition of maleic anhydride plasma polymer thin films. Measurements were performed on a FTIR spectrometer iS50 (Thermo Scientific) equipped with a high sensitive, low noise, MCT detector and coupled with a Grazing angle Germanium ATR accessory (VariGATR, Harrick Scientific Products). The angle of incidence was $65^{\circ}$. Spectra were collected at wavenumbers ranging from 650 to 4000

$161 \mathrm{~cm}^{-1}$, with a resolution of $4 \mathrm{~cm}^{-1}$ and a total of 64 scans. A minimum of three spectra were

162 recorded for each sample. The values are mean of two independent experiments. It is worthwhile to notice here that each sample was immediately analyzed after being removed from the plasma chamber.

\subsubsection{X-ray Photoelectron Spectroscopy (XPS)}

X-ray Photoelectron Spectroscopy (XPS) analyses have been performed to determine outermost surface chemistry of the deposited films using a VG SCIENTA SES 2002 spectrometer operating at $420 \mathrm{~W}$. The instrument was equipped with a concentric hemispherical analyzer. Al anode emitting $\mathrm{K} \alpha 1,2$ anode $(1486.6 \mathrm{eV})$ was monochromatized. Emitted photo electrons were collected at a take-off angle of $90^{\circ}$ from the substrate with electron detection in constant analyzer energy mode. Survey spectrum was recorded with a pass energy of $500 \mathrm{eV}$ and a step

172 size of $0.5 \mathrm{eV}$ whereas for high resolution spectra (C1s and $\mathrm{O} 1 \mathrm{~s})$ pass energy was set to $100 \mathrm{eV}$

173 with a step size of $0.1 \mathrm{eV}$, selecting a spot size of approximately $4 \times 6 \mathrm{~mm}^{2}$. Peak fitting was

174 carried out with mixed Gaussian-Lorentzian (30\%) components with equal full-width-at-halfmaximum (fwhm) values using CASAXPS software (CASA Software Ltd version 2.3.18). The

176 surface composition expressed in at.\% was determined using integrated peak areas of each

177 components and takes into account transmission factor of the spectrometer, mean free path and 
178 Scofield sensitivity factors of each atom (C1s: 1.00, O1s: 2.93). Standard deviation has been

179 estimated from measurements performed onto two substrates obtained from two different 180 plasma runs.

\subsubsection{Ellipsometry}

182 The coating thickness was estimated using ellipsometry with a phase modulation Multiskop 183 (M-033k001, Physik Instrumente). The sample was placed between the laser source arm and

184 the detector arm so as to be exposed to laser radiation at $532 \mathrm{~nm}$ (Nd:YAG laser). The cross 185 section of the laser beam is about $1 \mathrm{~mm}^{2}$. Average value of thickness was calculated with at 186 least five measurements performed in air at different positions of the sample by considering a 187 Cauchy model.

\subsubsection{Atomic Force Microscopy (AFM)}

189 Surface roughness measurements were performed using a FlexAFM scanning probe 190 microscope running with a Nanosurf C3000 controller (Nanosurf) in air. A silicon cantilever

191 was used for all measurements. The spring constant of the cantilever was 13-77 $\mathrm{N} \mathrm{m}^{-1}$. Tapping 192 mode was used and at least five scans were performed using 256 X 256 lines at different sample 193 locations to check the uniformity of the surface. Only $2 \mu \mathrm{m} \times 2 \mu \mathrm{m}$ images, obtained at the 194 center of each sample, are presented in the Supporting Information. Data processing and data 195 analysis were performed using Gwyddion software. In particular, the mean roughness (Sa) has 196 been selected in this study.

\subsubsection{Optical Emission Spectroscopy (OES)}

198 The plasma discharge was analyzed by Optical Emission Spectroscopy (OES), which is 199 particularly useful in order to detect the active species formed during the deposition and to understand the large variety of chemical processes occurring within the plasma glow discharge. 
201 Plasma emission spectra were obtained using a Horiba Scientifific - IHR 550 202 spectrophotometer coupled with CDD multichannel detector. The light emission was captured 203 with silicon oxide optical fibers placed at the different locations of the sample (P1 to P5). The 204 spectrophotometer was calibrated using the lab fluorescent tube lamp (atomic mercury line at $205485.833 \mathrm{~nm}$ ). A dark spectrum was subtracted from each spectrum. Spectral integration times 206 were optimized for each plasma condition to obtain a strong signal. Typical integration times 207 varied from 1 to 5 s. All data were processed with Syner Jobin Yvon V35 software. When OES 208 measurements were performed, an additional flow of $\operatorname{Ar}(2 \mathrm{sccm})$ was injected in the reactor at 209 the gas inlet (Figure 1).

\section{$2103 \quad$ Results and Discussion}

\subsection{Macroscopic kinetics of maleic anhydride plasma polymerization}

212 To understand and control plasma polymer deposition, Yasuda et al. introduced a methodology 213 consisting of measuring the deposition rate of the plasma polymer as a function of the specific 214 energy provided to the precursor. ${ }^{[39]}$ The evolution of the deposition rate with the specific 215 energy enabled to distinguish between an energy-deficient regime, where deposition rate 216 increased with specific energy, and energy-excess regimes, where deposition rate remained 217 constant or even decreased by increasing specific energy due to substantial etching processes 218 of the deposited plasma polymer. Derived from Yasuda's formalism based on the concept of 219 quasi-chemical equilibrium, other authors have preferred a so-called macroscopic approach to 220 describe plasma polymerization and comment on the deposition rate of plasma polymer. This 221 second approach, formulated by Hegemann et al., takes into account geometrical parameters of 222 the reactor such as plasma expansion and corresponding absorbed power. ${ }^{[5]}$ They proposed to 223 follow the evolution of the deposition rate of the plasma polymer at various specific energies 
224 in order to have access to one or more apparent activation energies $\left(E_{a}\right)$ related to a specific 225 state of the precursor, using a modified Arrhenius approach as shown in Equation 2:[7,25,40,41,42]

$$
\left(\frac{R}{F}\right)=G \times \exp \left(\frac{E_{a}}{W / F}\right)
$$

with $\mathrm{R}$ the deposition rate of the plasma polymer, $\mathrm{F}$ the precursor flow rate, $\mathrm{G}$ a factor depending on the operational conditions of the reactor, $\mathrm{E}_{\mathrm{a}}$ the apparent activation energy corresponding to a given state of the precursor, and $\mathrm{W}$ the average energy delivered by the generator. From 230 Equation 2, an Arrhenius-type plot depicting $\ln (\mathrm{R} / \mathrm{F})$ as a function of the inverse of the specific 231 energy given to the system $(\mathrm{W} / \mathrm{F})^{-1}$ can be used to identify different polymerization regimes. 232 Indeed, the slope of this curve is equal to the activation energy at the corresponding specific 233 energy regime. This apparent activation energy might then be compared with bonding energies 234 of the precursor to get information on the polymerization mechanism in the different 235 polymerization regimes. ${ }^{[5]}$ Therefore, knowledge of the real available energy per monomer 236 molecule in the plasma is required depending on absorbed power and plasma expansion. Note 237 that here delivered power is considered instead, which still allows comparison of the different 238 positions and regimes by discussing 'apparent' activation energies.

239 This formalism has been applied in this work in order to control the deposition of maleic 240 anhydride plasma polymer synthesized by pulsed plasma polymerization performed in a low241 pressure RF plasma reactor. As illustrated in Figure 1, a $1 \mathrm{~m}$ long plasma reactor enables to 242 conduct simultaneously plasma polymerization in different locations of the plasma discharge: 243 in a pre-discharge zone (position P1), in the discharge zone (position P3) and in the post244 discharge zone (position P5).

245 Figure 2 shows the Arrhenius-type plots representing the natural logarithm of the deposited 246 thickness per flow rate unit versus the inverse specific energy provided by the generator at three 247 relevant positions within the reactor, namely $\mathrm{P} 1$ in the pre-discharge zone, P3 in the glow 
248 discharge and P5 in the post-discharge zone. Here, it is worthwhile to notice that all the 249 deposition rates were extracted from graphs depicting the thicknesses as a function of 250 deposition times for all experimental conditions. These graphs are shown in Figure S3 of the 251 Supporting Information.
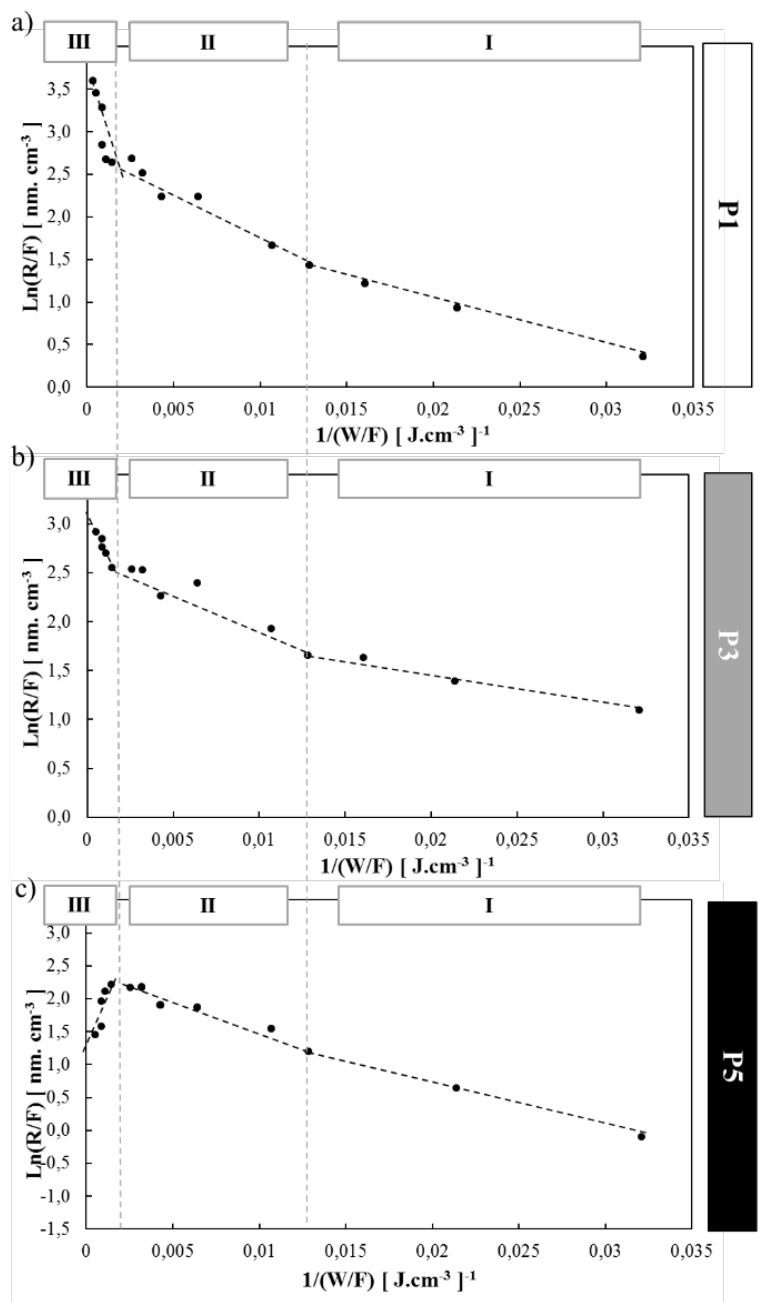

253 Figure 2. Arrhenius-type plot describing the deposition of the plasma polymer as a function of 254 the inverse of the specific energy provided to the precursor during pulsed plasma 255 polymerization of maleic anhydride: (a) for the pre-discharge zone (P1) close to the gas inlet, (b) for the discharge zone (P3) and (c) for the post-discharge zone (P5) towards the pump.

257 Three domains of maleic anhydride plasma polymer growth are clearly observed for any sample 258 position: i) the first regime (I) is observed at low energy input showing typical deposition rates, 
e.g., at P3 around $4 \mathrm{~nm} \mathrm{~min}^{-1}$. From the slope of the linear fits, apparent activation energies can be calculated (Table 1). They are equal to $13 \pm 1 \mathrm{eV}, 7 \pm 1 \mathrm{eV}$ and $16 \pm 2 \mathrm{eV}$ per precursor molecule respectively for P1 (pre-discharge zone), P3 (discharge zone) and P5 (post-discharge zone). These activation energies are higher than any bond dissociation energy of the precursor, particularly higher than the $\Pi$ bond of the $\mathrm{C}=\mathrm{C}(2.8 \mathrm{eV})$, which theoretically ensures sufficient energy to initiate plasma polymerization via a radical mechanism. Note, however, that nominal power values were used here, which are likely to be distinctly higher than absorbed power values in the active plasma zone required to properly calculate $E_{a}$. Hence, despite of these high values of apparent activation energies, the growth rate of the plasma polymer is limited in this regime by the input power delivered by the generator: the increase in the deposition rate originates from an increase of the specific energy (from the left to the right of the graph). It is worthy to note that differences in terms of apparent activation energy can be observed between the different positions in this first regime. This point will be discussed in more detail later. ii) When the specific energy is increased, a slope change is observed giving rise to a second regime (II) with higher apparent activation energies. This slope change indicates the dissociation of new chemical bonds within maleic anhydride and an increase in the film growth rate. Interestingly, at this energy input level, the values of activation energies corresponding to the different reactor zones are very close: $25 \pm 4 \mathrm{eV}, 20 \pm 2 \mathrm{eV}$ and $22 \pm 2 \mathrm{eV}$ per molecule respectively for P1, P3 and P5 (Table 1). It can be noted that these activation energies are again overestimated with respect to bond dissociation energies of the precursor, however, indicating a higher degree of precursor fragmentation. iii) With further increasing specific energy, a third growth regime (III) appears. In this regime, different growth behaviors are observed for the three positions. In the pre-discharge zone and the discharge zone a slope deviation appears, indicating an increase in the growth rate with the increase of the energy input reaching $\mathrm{R}=$ $24 \mathrm{~nm} \mathrm{~min}{ }^{-1}$ for $\mathrm{P} 1$. The slope deviation is less pronounced for P3 reaching a lower $\mathrm{R}=$ 
$28414 \mathrm{~nm} \mathrm{~min}^{-1}$, probably because competitive mechanisms come into play. These mechanisms 285 include not only a probable polymer etching (e.g. due to enhanced formation of reactive oxygen 286 species by fragmentation) but also a balance between plasma polymerization as the form of thin 287 film and nanoparticles formation. Indeed, powder particles were observed in the post-discharge 288 zone after P5 (see Figure S4 in Supporting Information). This third growth regime, 289 corresponding to a more complex growth mechanism, is mostly highlighted within the post290 discharge zone (P5) and leads to a significant decrease in deposition rate from the highest 291 measured value $\mathrm{R}=7 \mathrm{~nm} \mathrm{~min}^{-1}$ at the II/III transition. More details about this powder formation 292 will be discussed in a forthcoming communication.

293 By using the macroscopic kinetics approach for plasma polymerization of maleic anhydride, 294 such different growth regimes could be identified depending on the energy input into the active 295 plasma zone and the position of the sample in the reactor. Consequently, different activation 296 energy values were determined for each regime. Now, in order to explain the obtained results 297 and to study in particular the spatio-temporal effect on the polymer qualitative variations in the 298 surface chemistry, chemical characterizations of thin films as well as plasma species analysis 299 were performed and discussed in the next part.

Table 1. Apparent activation energies involved during pulsed plasma polymerization of

301 maleic anhydride for the different reactor zones in the different growth regimes with

302 increasing energy input from I to III.

\begin{tabular}{|c|c|c|c|c|c|c|c|c|c|}
\hline \multirow{2}{*}{$\begin{array}{l}\text { Positions } \\
\text { Regimes }\end{array}$} & \multicolumn{3}{|c|}{ P5 (post-discharge) } & \multicolumn{3}{|c|}{ P3 (discharge) } & \multicolumn{3}{|c|}{ P1 (pre-discharge) } \\
\hline & III & II & $\mathbf{I}$ & III & II & I & III & II & I \\
\hline$E_{a}(e V)$ & $\begin{array}{l}\text { Competitive } \\
\text { mechanisms }\end{array}$ & $22 \pm 2$ & $16 \pm 2$ & $\begin{array}{l}\text { Competitive } \\
\text { mechanisms }\end{array}$ & $20 \pm 2$ & $7 \pm 1$ & $150 \pm 22$ & $25 \pm 4$ & $13 \pm 1$ \\
\hline
\end{tabular}



in various growth regimes and various positions

306 Complementary to the kinetics study based on the evolution of the polymer growth rates as a 307 function of the specific energy and the position of the sample in the reactor, poly maleic 308 anhydride plasma polymer thin films have been chemically characterized in order to identify qualitative variations in the chemical fingerprint of the plasma coatings (resulting from differences in fragmentation of the precursor molecule) according to the growth regime and also to the location from the plasma discharge. Systematically, samples corresponding to the inverse specific energy $2.14 \cdot 10^{-2}\left[\mathrm{~J} \mathrm{~cm}^{-3}\right]^{-1}\left(\mathrm{P}_{\mathrm{g}}=30 \mathrm{~W}, \mathrm{DC}=2 \%\right), 0.43 \cdot 10^{-2}\left[\mathrm{~J} \mathrm{~cm}^{-3}\right]^{-1}\left(\mathrm{P}_{\mathrm{g}}=30 \mathrm{~W}\right.$, $\mathrm{DC}=10 \%)$ and $0.09 \cdot 10^{-2}\left[\mathrm{~J} \mathrm{~cm}^{-3}\right]^{-1}\left(\mathrm{P}_{\mathrm{g}}=30 \mathrm{~W}, \mathrm{DC}=50 \%\right)$ for each position were analyzed to

314 represent the chemical composition of maleic anhydride) plasma polymer synthesized in regimes I, II and III, respectively. The thickness of the plasma polymer thin films was set to 50 $\mathrm{nm}$. It should be noted that the morphology of the polymer thin films will not be discussed in this paper, since AFM images obtained at different locations on the surface of each sample 318 proved the existence of a homogenous, smooth polymer thin film regardless of its position from 319 P1 to P5 and of the growth regime (see Figure S5 in Supporting Information).

Typical high resolution XPS spectra of the C1s for maleic anhydride plasma polymer indicate hydrocarbon $\left(\underline{\mathbf{C}}-\mathrm{C}, \underline{\mathbf{C H}}_{\mathrm{x}}\right.$ at $\left.285.0 \mathrm{eV}\right)$, carbon in alpha position of anhydride/carboxylic acid/ester groups $(\underline{\mathbf{C}}-\mathrm{C}=\mathrm{O}$ at $285.6 \mathrm{eV})$, carbon singly bonded to oxygen $(\underline{\mathbf{C}}-\mathrm{OR}$ at $286.5 \mathrm{eV})$, carbon doubly bonded to oxygen $(\underline{\mathbf{C}}=\mathrm{O}$ at $287.9 \mathrm{eV})$ and anhydride groups/carboxylic acid/ester groups $(\mathrm{O}=\underline{\mathrm{C}}-\mathrm{O}-\underline{\mathrm{C}}=\mathrm{O} / \mathrm{O}-\underline{\mathrm{C}}=\mathrm{O}$ at $289.5 \mathrm{eV})$ (see Figure $\mathrm{S} 6$ in Supporting Information).

Figure 3 shows the relative areas of three relevant peaks for samples fabricated in the different

326 growth regimes and at different positions: the $\mathrm{O}=\underline{\mathbf{C}}-\mathrm{O}-\underline{\mathbf{C}}=\mathrm{O} / \mathrm{O}-\mathrm{C}=\mathrm{O}$ peak representative of 327 anhydride, carboxylic and ester groups and the $\underline{\mathbf{C}}-\mathrm{C}, \underline{\mathbf{C}} H \mathbf{x}$ or $\underline{\mathbf{C}}-\mathrm{OR}$ peak representative of 
328 monomer fragmentation. As expected, moving from regime I to III leads to the decrease in the 329 concentration of anhydride, carboxylic and ester groups, especially from the regime I to II, and 330 an increase in the concentration of C-OR related to the creation of new types of oxygenated 331 functionalities due to high fragmentation degree of the precursor. It should be noted that the 332 possible ring opening of the anhydride to form the acid is not visible by XPS since the binding 333 energies of the two carbons are the same. The increase in the hydrocarbon group content from 334 regime I to II indicates a probable rise in the crosslinking of the plasma polymer matrix when 335 the energy input increases. The drop in this relative area in the third regime could be explained 336 by the presence of many residual free radicals on the surface at the end of the polymerization, 337 which can instantly react with atmospheric oxygen when the samples were recovered. 

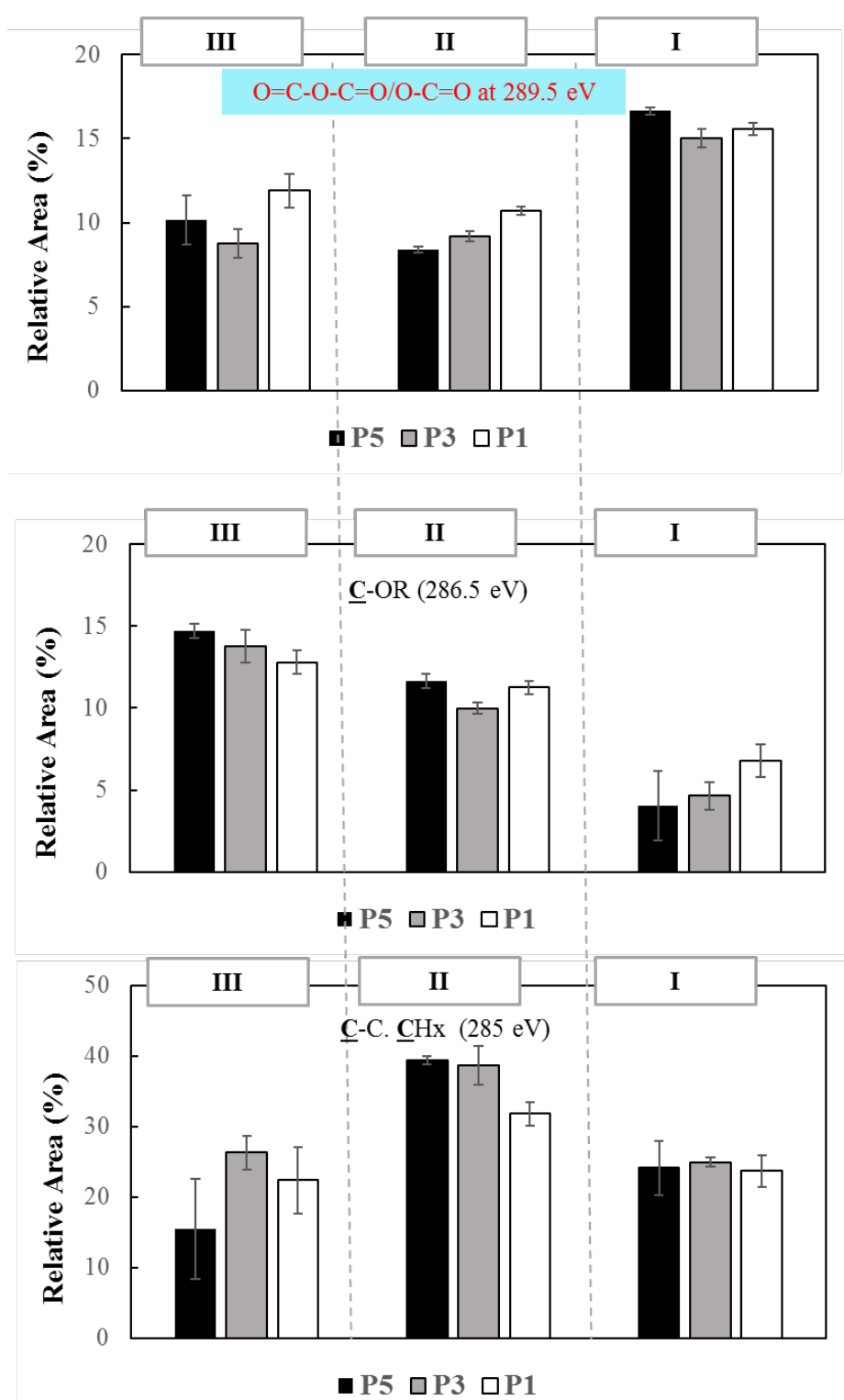

339 Figure 3. Relative areas of different functionalities present in the high resolution C1s peak

340 (measured by XPS) for maleic anhydride plasma polymer prepared in various growth regimes

341 at different positions (error bars correspond to the standard deviation).

342 Moreover, the inhibition of the polymerization occurred due to the production of oxygen-rich

343 plasma species coming from monomer fragmentation at high energies, in accordance with the

344 high oxygen content for the samples obtained in this regime (Figure 4). In fact, the

345 stoichiometric ratio calculated from the wide scan XPS spectra increases from $\mathrm{O} \backslash \mathrm{C}=0.25$ to

3460.43 from regime II to III, i.e. with increasing energy input. 


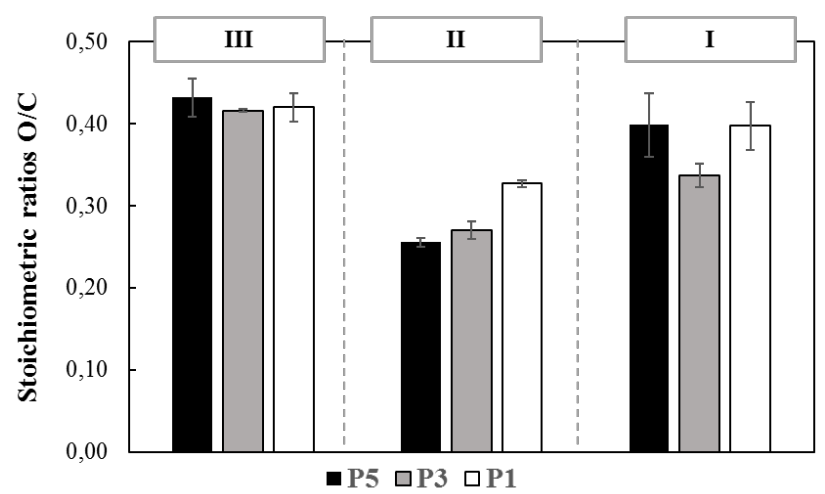

Figure 4. O/C stoichiometric ratios in maleic anhydride plasma polymer determined by wide scan XPS analyses in the different growth regimes at various positions (error bars correspond to the standard deviation).

351 To complete these XPS results, ATR FTIR analyses were performed on the plasma polymers 352 prepared in the three regimes and the three positions. In accordance with the literature, the 353 characteristic vibration bands of maleic anhydride plasma polymer were identified: asymmetric $354 \mathrm{C}=\mathrm{O}$ stretching $\left(1860 \mathrm{~cm}^{-1}\right)$, symmetric $\mathrm{C}=\mathrm{O}$ stretching $\left(1780 \mathrm{~cm}^{-1}\right)$, cyclic conjugated 355 anhydride group stretching $\left(1230 \mathrm{~cm}^{-1}-1170 \mathrm{~cm}^{-1}\right), \mathrm{C}-\mathrm{O}-\mathrm{C}$ stretching $\left(1082 \mathrm{~cm}^{-1}-1061 \mathrm{~cm}^{-1}\right)$ 356 and cyclic unconjugated anhydride group stretching $\left(923 \mathrm{~cm}^{-1}-908 \mathrm{~cm}^{-1}\right){ }^{[24,31]}$ In addition, 357 the formation of carboxylic acid groups due to cyclic anhydride ring opening for some operating 358 conditions induces a peak at $1730 \mathrm{~cm}^{-1}(\mathrm{C}=\mathrm{O}$ stretching). The evaluation of the fragmentation 359 rate of anhydride groups has been performed by calculating the intensity ratio between the 360 intensity of the peak of $\mathrm{C}=\mathrm{O}$ stretching originating from carboxylic acid groups ( $\mathrm{I}_{\text {acid, }}$ at $3611730 \mathrm{~cm}^{-1}$ ) and the intensity of the peak of symmetric $\mathrm{C}=\mathrm{O}$ stretching coming from anhydride 362 groups $\left(\mathrm{I}_{\mathrm{anh}}\right.$, at $\left.1780 \mathrm{~cm}^{-1}\right)$ (all relevant information can be found in Supporting Information, 363 Figure S7). However, it should be noted that this ratio is not an absolute value but a relative one 364 since no internal reference has been used to calculate this ratio. Figure 5 summarizes the results 365 of these calculations since it depicts the evolution of the ratio $\mathrm{I}_{\text {acid }} / \mathrm{I}_{\text {anh }}$ for the different regimes for each reactor zone. 


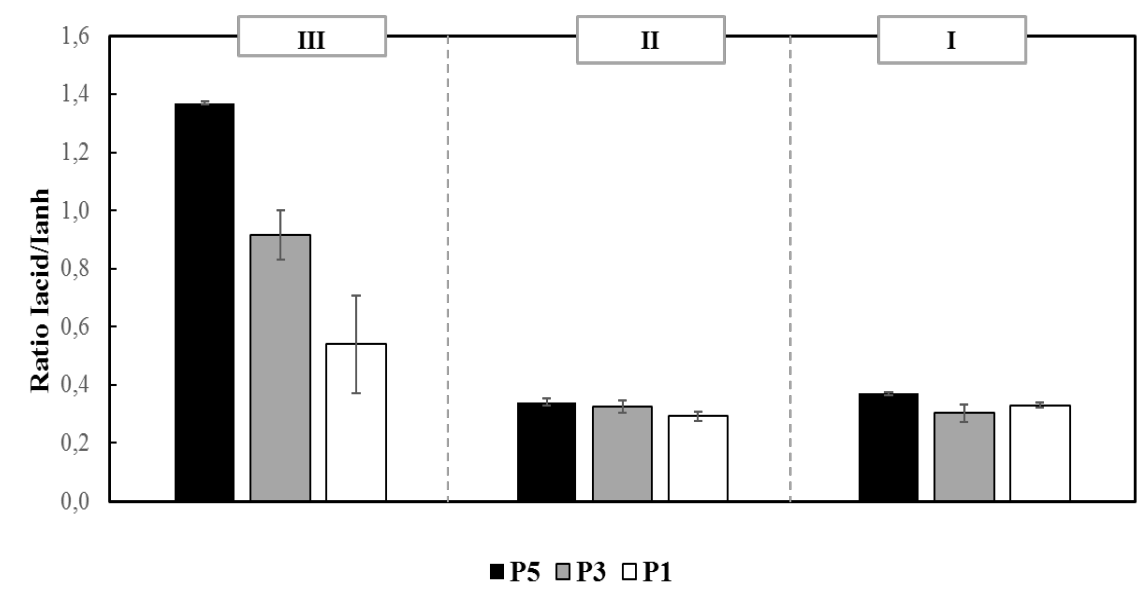

368 Figure 5. Evolution of the ratio between the intensity of the peak at $1730 \mathrm{~cm}^{-1}$ and the intensity of the peak at $1780 \mathrm{~cm}^{-1}\left(I_{a c i d} / I_{a n h}\right)$ measured by ATR FTIR for maleic anhydride plasma polymer synthesized in various growth regimes in the three reactor zones (P1, P3 and P5) (Error bars correspond to the standard deviation).

372 Whatever the position is, no difference is observed between the different samples prepared in 373 the regimes I and II, indicating position-independent film growth mechanisms. Therefore, 374 despite a difference in term of analysis thickness between XPS and ATR FTIR, one can consider 375 that going from regime I to II entails a lack of anhydride (and corresponding acid) groups within 376 the plasma polymer, namely a higher precursor fragmentation. Indeed, the XPS analyses 377 showed that there were less anhydride (and corresponding acid/ester) groups in the regime II in comparison to the first regime, while no difference appeared in the ratio $I_{a c i d} / I_{a n h}$ by ATR FTIR.

379 On the contrary, significant differences in anhydride versus acid content can be observed for 380 the samples prepared in the third regime (at high specific energy) for the three positions. $\mathrm{I}_{\text {acid }} / \mathrm{I}_{\text {anh }}$ 381 ratios were much higher than the ones calculated in the other regimes, especially for P5. 382 Regarding the influence of the position, more acid formation occurred when the sample was 383 prepared in the discharge zone and even more in the post-discharge zone compared to the pre384 discharge zone. This result may originate from higher fragmentation of the precursor along the 385 precursor flow within the reactor. 
To try to summarize and interpret the results provided by the Arrhenius-type plots describing 387 the polymer growth kinetics as well as the surface characterizations by XPS and FTIR, three 388 growth regimes can be observed when the specific energy increases:

389 i) A first regime is identified at low specific energy, where the energy provided to the precursor 390 is limited and enables a low fragmentation of the monomer, whatever the position is. In this 391 regime, it also seems that the energy provided by the generator is not fully transmitted to the 392 precursor vapor according to the location in the reactor. Indeed, different activation energies were calculated depending on the position whereas the surface chemistry was similar. The existence of an experimental factor $\left(\mathrm{S}_{\exp }\right)$ which probably takes into account power losses, the spatial dimensions of the reactor and of the plasma may explain these results, as previously reported by Hegemann et al. ${ }^{[1,43,44]}$ We can thus presume that the calculated activation energy $\mathrm{E}_{\mathrm{a} \text { (measured) }}$ is a result of the multiplication of the real activation energy $\mathrm{E}_{\mathrm{a}(\text { real }}$ by an experimental factor $S_{\exp }$ as shown in Equation 3.

$$
E_{a(\text { measured })}=E_{a(\text { real })} \times S_{\text {exp }}
$$

The complexity of maleic anhydride plasma polymerization as well as other factors, that will

401 be discussed later, make the determination of this experimental factor very difficult, which, 402 however, should enable a $\mathrm{E}_{\mathrm{a}(\mathrm{real})}$ in accordance with a partial fragmentation of the monomer (see 403 section 3.3). Anyhow, at this level of specific energy, the experimental factor seems to depend 404 highly on the geometrical characteristics of the reactor and the plasma discharge, which leads 405 to different $E_{a}$ (measured) values depending on the position in the reactor. It can be also noted that 406 the activation energies obtained at P1 and P5 are very close and can reflect probably the 407 presence of a symmetric plasma discharge within the reactor, P3 being a central position with 408 respect to specific energies as used in regime $\mathrm{I}$. 
409 ii) A second regime at moderate specific energy is observed, where activation energies are 410 higher, which is in accordance with more fragmentation of the precursor, as revealed by XPS 411 analyses. The activation energy values again appear to be too high supporting the presence of 412 the discussed experimental factor. However, in this regime, similar values of activation energy 413 and similar surface chemistries, whatever the position is, suggest a film growth rate irrespective 414 of a geometrical parameter, probably due to a uniform plasma expansion ranging to both sides, 415 i.e. P1 and P5. Therefore, the experimental factor $\mathrm{S}_{\exp }$ seems to be dependent on geometrical 416 parameters mostly at low specific energy but also on the input power, which seems to prevail 417 here. Indeed, reaching a certain value of input power, the distance of the sample from the plasma 418 discharge, at least close to the plasma glow discharge, does not seem to influence much the 419 chemical nature of the plasma species and thus leads to a constant value of the activation energy whatever the position. The existence of this energy threshold from which the experimental 421 factor becomes independent of geometrical parameters will be confirmed later.

422 iii) Finally, a third regime of plasma polymer growth can be identified at high specific energy, 423 where fragmentation of the precursor and/or simultaneous degradation of the growing polymer 424 occurs (more C-OR groups in XPS spectra, more acid formation observed in ATR FTIR spectra). In this regime, the influence of the position of the sample within the reactor is no

426 longer negligible, according to FTIR analyses. Therefore, it is not meaningful to discuss the 427 activation energies, especially for the P3 and P5 positions. In fact, a complex polymer growth 428 mechanism occurred, with a competition of plasma polymerization and degradation of the 429 precursor and the growing plasma polymer. 
432 In order to validate the previous conclusions made based on the kinetics study and the 433 characterization of maleic anhydride plasma polymer synthesized in various operating 434 conditions, the analysis of the chemical composition of the plasma phase at different reactor 435 zones and for different deposition conditions was performed by Optical Emission Spectroscopy 436 (OES). In this study, a qualitative analysis of the plasma phase was carried out to identify 437 relevant bands present in the obtained spectra in order to try to correlate the properties of plasma 438 polymer thin films with the presence of specific species in the plasma phase. All spectra 439 correspond to plasma species emitting in a spectral range from $200 \mathrm{~nm}$ to $800 \mathrm{~nm}$ obtained 440 during plasma polymerization of maleic anhydride. As shown in Figure 6, OES showed that the 441 plasma phase mainly contains $\mathrm{CO}$ species but also $\mathrm{CH}$ species and atomic hydrogen $(\mathrm{H} \alpha)$. 442 According to the literature, ${ }^{[45-47]}$ the following systems have been identified within the range of 443 the wavelengths considered in this work: the 4th Positive System $\mathrm{CO}\left(\mathrm{A}^{1} \Pi \rightarrow \Sigma^{1} \mathrm{X}^{+}\right)$and the 4441 st Negative System $\mathrm{CO}^{+}\left(\mathrm{B}^{2} \Sigma^{+} \rightarrow \mathrm{X}^{2} \Sigma^{+}\right)$between $200 \mathrm{~nm}$ and $260 \mathrm{~nm}$, whose lines intensities 445 were very weak. The most intensive emission lines correspond to the 3rd Positive and 5B 446 Systems of $\mathrm{CO}\left(\mathrm{b}^{3} \Sigma^{+} \rightarrow \mathrm{a}^{3} \Pi\right.$, from 260 to $\left.350 \mathrm{~nm}\right)$ as well as the Angström System $\mathrm{CO}\left(\mathrm{B}^{1} \Sigma^{+}\right.$ $447 \rightarrow \mathrm{A}^{1} \Pi$ from 400 to $570 \mathrm{~nm}$ ). More details about the lines identification are given in Table S2 448 in Supporting Information. By comparing the spectra obtained at different polymerization times, 449 specific energies and positions in the reactor, no new line was observed by changing the 450 operating conditions, only the intensities of the peaks were slightly changing (see Figure S8 in 451 Supporting Information). The emitting species were thus the same but their relative content 452 slightly changed from one condition to the other. It can also be noted that a steady state was 453 reached in less than $20 \mathrm{~s}$, since no difference was observed between spectra recorded at various 454 polymerization times. Lines corresponding to atomic elements such as atomic carbon eg. C(I) 455 at $247.9 \mathrm{~nm},{ }^{[48]}$ ionic carbon C(II) at $251.2 \mathrm{~nm}, 392.0 \mathrm{~nm}, 426.7 \mathrm{~nm}^{[48,49]}$ or atomic oxygen eg. 
$\mathrm{O}$ (I) at $777.0 \mathrm{~nm}^{[50]}$ were not visible, which indicates that the total fragmentation of the monomer was not achieved in the studied operating conditions. This result is noteworthy since very high activation energies were calculated (based on generator power values) by the macroscopic approach used to describe the growth rate of the plasma polymer as a function of

460 the specific energy. Hence, the OES results also support the existence of an experimental factor 461 ( $\left.\mathrm{S}_{\mathrm{exp}}\right)$ in the calculation of apparent activation energies, as described before. Additional analyses 462 are still necessary to fully interpret OES spectra and relate them to a precise polymerization 463 mechanism.

Moreover, it is known that inductively coupled plasma (ICP) is subject to a mode transition between capacitively coupled or electrostatic mode (called E mode) and inductively coupled or electromagnetic mode (called $\mathrm{H}$ mode) to sustain the plasma discharge. ${ }^{51}$ This $\mathrm{E} \rightarrow \mathrm{H}$ mode transition occurs above a certain threshold value of input RF power when a sudden jump in the electron density and light emission is observed. ${ }^{52}$ In order to illustrate this mode transition, the 469 intensities of argon lines observed in OES spectra at 738.3, 750.4, 751.5 and $811.5 \mathrm{~nm}$ (Figure 6) were used here as a probe of the density of atoms in a metastable state. ${ }^{53}$ The evolution of 471 the Ar line intensity at $738.3 \mathrm{~nm}$ as a function of the inverse specific energy (Figure S9 in 472 Supporting Information) for the three reactor zones shows a transition point from $\mathrm{E}$ to $\mathrm{H}$ mode 473 at the beginning of the second regime. This critical value of $1 /(\mathrm{W} / \mathrm{F})$ can be estimated around $4741.3 \cdot 10^{-2}\left[\mathrm{~J} \mathrm{~cm}^{-3}\right]^{-1}$. When specific energy increases beyond this critical value, or energy 475 threshold, (from the right to the left in Figure S9), the electron density $n_{e}$ is enhanced, but no 476 significant jump in the deposition rate is observed and the deposition rates even become very 477 similar whatever the reactor zone. The $\mathrm{E} \rightarrow \mathrm{H}$ transition is typically accompanied by a drastic 478 change in the electron energy distribution function (eedf), that is, an increase in $\mathrm{n}_{\mathrm{e}}$ and a 479 decrease in electron temperature $\mathrm{T}_{\mathrm{e}}{ }^{\left[{ }^{[5]}\right.}$ Hence, the apparent low dependency of deposition rates 
480

481

482

483

484

on changes in eedf in this regime corroborates the used macroscopic approach indicating that the specific energy delivered per monomer molecule is indeed a key factor in plasma polymerization. Conditions might apply, where the plasma expands rather uniformly to positions $\mathrm{P} 1$ and $\mathrm{P} 5$ at sufficiently high $\mathrm{T}_{\mathrm{e}}$ resulting in the observed comparable activation energies and geometrical factors $\mathrm{G}$ (in Equation 2). ${ }^{[5]}$ Lower plasma expansion in regime I (E mode), on the contrary, requires that different $S_{\text {exp }}$ values (in Equation 3) need to be applied for the different positions.

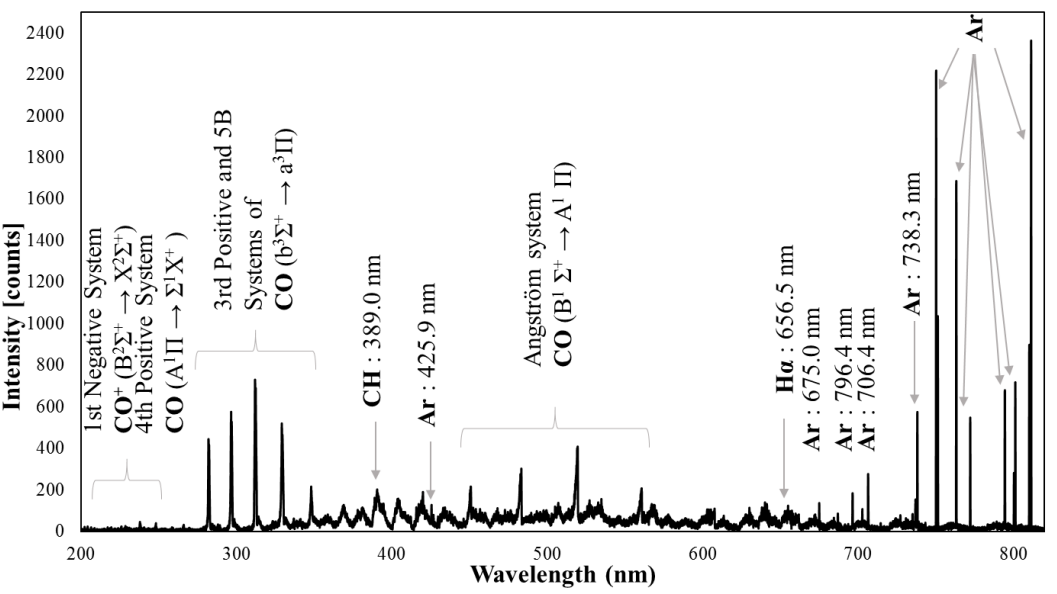

Figure 6. Optical emission spectrum of maleic anhydride during plasma polymerization in regime $I I$, in the discharge zone (P3)

\section{Conclusions}

Pulsed plasma polymerization of maleic anhydride has been investigated in an original $1 \mathrm{~m}$ long

RF plasma reactor, operating at low pressure. By using a macroscopic approach to describe film growth kinetics as a function of the specific energy provided to the precursor by the plasma, we were able to identify different growth regimes during plasma polymerization of maleic anhydride. The apparent activation energies were derived corresponding to each regime for the 
different reactor zones (pre-discharge, discharge, post-discharge): (i) a first regime at low input energy was observed. In this regime, the calculated activation energy is a result of the multiplication of the real activation energy by an experimental factor $\left(\mathrm{S}_{\mathrm{exp}}\right)$ taking account of

501 (undetermined) power losses and plasma expansion. The existence of this experimental factor 502 ( $\left.\mathrm{S}_{\mathrm{exp}}\right)$ is consistent with the low fragmentation of the precursor as observed in XPS and ATR 503 FTIR spectra. Noteworthy, $\mathrm{S}_{\text {exp }}$ is strongly dependent on geometrical parameters of the reactor and the plasma discharge since different activation energy values were determined depending on the position in the reactor; (ii) a second regime at moderate specific energy corresponds to higher activation energies and stronger precursor fragmentation during deposition. Herein, the experimental factor $\left(\mathrm{S}_{\mathrm{exp}}\right)$ still exists but no longer depends on the examined positions, probably

508 due to a transition from $\mathrm{E}$ to $\mathrm{H}$ mode as identified by OES; (iii) a last regime was obtained at high specific energy, where different polymer chemistries and different growth behaviors were observed depending on the position. Deposition rates were found to decrease along the gas flow in the reactor. A complex growth mechanism including polymer deposition, particles formation

512 but also etching was likely to take place. As a conclusion, this study in an original reactor 513 allowed us to gain insights into the kinetics of plasma polymerization of maleic anhydride by 514 combining a temporal control of the polymerization, using the pulsed mode, and a spatial control of the polymerization, exploiting the unique configuration of the $1 \mathrm{~m}$ long reactor. This evidence of a possible spatio-temporal control of plasma polymerization paves the way to get

517 further understanding of complex polymer deposition that may be observed when functional 518 polymer coatings with diverse surface properties are fabricated according to their location in 519 the plasma discharge. 


\section{Acknowledgments}

523 The authors are grateful for the financial supports provided by the Institut Carnot MICA and

524 the ANRT (Grant n ${ }^{\circ}$ 2017/0966). They also would like to thank Philippe Fioux and Simon Gree

525 for their help with surface characterizations and access to the XPS and IR spectroscopy

526 platforms. This manuscript is in honor of the 50 year anniversary of the French Polymer Group

527 (Groupe Français des Polymères - GFP).

528

529 Received: ((will be filled in by the editorial staff)); Revised: ((will be filled in by the editorial

530 staff)); Published online: ((please add journal code and manuscript number, e.g., DOI:

531 10.1002/ppap.201100001))

532

533 Keywords: Activation energy; Macroscopic approach; Maleic Anhydride; OES; PECVD

535 References

536 [1] D. Hegemann, E. Körner, S. Chen, J. Benedikt, A. von Keudell, Appl. Phys. Lett. 2012, $537 \quad 100,5.051601$.

538 [2] H. Yasuda, Luminous Chemical Vapor Deposition and Interface Engineering, CRC 539 Press 2004.

540 [3] H. Yasuda, T. Yasuda, J. Polym. Sci. Part A Polym. Chem. 2000, 38, 6.

541 [4] H. K. Yasuda, Plasma Polymerization, Academic Press 2012.

542 [5] D. Hegemann, E. Bülbül, B. Hanselmann, U. Schütz, M. Amberg, S. Gaiser, Plasma 543 Process. Polym. 2020, e2000176. 
544 [6] D. Hegemann, E. Körner, S. Guimond, Plasma Process. Polym. 2009, 6.

545 [7] D. Hegemann, M. M. Hossain, E. Körner, D. J. Balazs, Plasma Process. Polym. 2007, 4, 5463.

547 [8] E. Körner, G. Fortunato, D. Hegemann, Plasma Process. Polym. 2009, 6, 2.

548 [9] D. Hegemann, Pure Appl. Chem. 2008, 80, 9.

549 [10] A. R. Denaro, P.A. Owens, A. Crawshaw,. Euro. Polym. J. 1968, 4, 1.

550 [11] M. J. Vasile, G. Smolinsky, J. Electrochem. Soc. 1972, 119, 4.

551 [12] H. Kobayashi, A.T. Bell, M. Shen, Macromolecules 1974, 7, 3.

552 [13] S. Ershov, F. Khelifa, V. Lemaur, J. Cornil, D. Cossement, Y. Habibi, P. Dubois, R. 553 Snyders, ACS Appl. Mater. Interfaces 2014, 6, 15.

554 [14] J. Friedrich, Plasma Process. Polym. 2011, 8, 9.

555 [15] A. Michelmore, P. M. Bryant, D. A. Steele, K. Vasilev, J. W. Bradley, R. D. Short, 556 Langmuir 2011, 27, 19.

557 [16] S. Saboohi, R. D. Short, B. R. Coad, H. J. Griesser, A. Michelmore, J. Phys. Chem. Lett. $558 \quad 2019,10,23$.

559 [17] H. Kobayashi, A. T. Bell, M. Shen, J. Appl. Polym. Sci. 1973, 17,3.

560 [18] R. d'Agostino, P. Favia, F. Fracassi, F. Illuzzi, J. Polym. Sci. Part A Polym. Chem. 1990, $56128,12$.

562 [19] R. d'Agostino, P. Favia, R. Förch, C. Oehr, M. R. Wertheimer, Plasma Process. Polym. $5632010,7,5$.

564 [20] D. Hegemann, D. A. Steele, R. D. Short, Plasma Process. Polym. 2010, 7, 5. 
[21] H. Yasuda, T. Hsu, J. Polym. Sci., Polym. Chem. Ed. 1977, 15 ,1.

566 [22] J. Friedrich, R. Mix, G. Kühn, I. Retzko, A. Schönhals, W. Unger, Composite Interfaces $5672003,10,2-3$.

568 [23] M. E. Ryan, A. M. Hynes, J. P. S. Badyal, Chem. Mater. 1996, 8, 1, 3.

569 [24] F. Siffer, A. Ponche, P. Fioux, J. Schultz, V. Roucoules, Anal. Chim. Acta 2005, 539, $570 \quad 1-2$.

571 [25] F. Bally-Le Gall, A. Mokhter, S. Lakard, S. Wolak, P. Kunemann, P. Fioux, A. Airoudj, 572 S. E. Yakhlifi, C. Magnenet, B. Lakard, V. Roucoules, Plasma Process. Polym. 2019, 16, 3.

573 [26] D. Korzec, D. Theirich, F. Werner, K. Traub, J. Engemann, Surf. Coatings Technol. 574 1995, 74-75, 67-74.

575 [27] L. M. H. Groenewoud, G. H. M. Engbers, J. G. A. Terlingen, H. Wormeester, J. Feijen, 576 Langmuir 2000, 16, 15.

577 [28] U. Lommatzsch, J. Ihde, Plasma Process. Polym. 2009, 6, 10.

578 [29] N. E. Blanchard, B. Hanselmann, J. Drosten, M. Heuberger, D. Hegemann, Plasma 579 Process. Polym. 2015, 12, 1.

580 [30] J. Trieschmann, D. Hegemann, J. Phys. D: Appl. Phys. 2011, 44, 47.

581 [31] S. Schiller, J. Hu, A.T.A. Jenkins, R.B. Timmons, F.S. Sanchez-Estrada, W. Knoll, R. 582 Förch, Chem. Mater. 2002, 14, 1.

583 [32] M. M. Brioude, M.P. Laborie, A. Airoudj, H. Haidara, V. Roucoules, Plasma Process. 584 Polym. 2014, 11, 10.

585 [33] L. Ploux, K. Anselme, A. Dirani, A. Ponche, O. Soppera, V. Roucoules, Langmuir 2009, $586 \quad 25,14$. 
[34] A. Airoudj, F. Bally-Le Gall, V. Roucoules, J. Phys. Chem. C 2016, 120, 51.

[35] E. Kulaga, L. Ploux, L. Balan, G. Schrodj, V. Roucoules, Plasma Process. Polym. 2014, $11,1$.

[36] A. Airoudj, G. Schrodj, M.-F. Vallat, P. Fioux, V. Roucoules, Int. J. Adhes. Adhes. 2011, 31,6 .

[37] M. Vauthier, L. Jierry, F. Boulmedais, J. C. Oliveira, K. F. A. Clancy, C. Simet, V. Roucoules, F. Bally-Le Gall, Langmuir 2018, 34, 40.

[38] M. Vauthier, L. Jierry, M. L. Martinez Mendez, Y. -M. Durst, J. Kelber, V. Roucoules, F. Bally-Le Gall, J. Phys. Chem. C. 2019, 123, 7.

[39] H. Yasuda, T. Hirotsu, J. Polym. Sci. Polym. Chem. Ed. 1978, 16, 4.

[40] D. Hegemann, H. Brunner, C. Oehr, Surf. Coatings Technol. 2001, 142-144, 849-855.

[41] D. Hegemann, E. Körner, K. Albrecht, U. Schütz, S. Guimond, Plasma Process Polym. 2010, 7,11 .

[42] M. Veuillet, L. Ploux,A. Airoudj, Y. Gourbeyre, E. Gaudichet - Maurin, V. Roucoules, Plasma Process. Polym. 2017, 14, 10.

[43] D. Hegemann, U. Schütz, Thin Solid Films 2005, 491, 1.

[44] D. Hegemann, Thin Solid Films 2006, 515, 4.

[45] F. Poncin-Epaillard, M. Aouinti, Plasmas and Polymers 2002, 17.

[46] C. Rond, A. Bultel, P. Boubert, B. G. Chéron, Chem. Phys. 2008, 354, 1-3.

[47] A. Granier, M. Vervloet, K. Aumaille, C. Vallée, Plasma Sources Sci. Technol. 2003, $12,1$. 
608 [48] H. Ling, X. K. Shen, Y. X. Han, Y. F. Lu, Proc. of SPIE, 2006, 6107, 61070A.

609 [49] O. Balki, Md. M. Rahman, H. E. Elsayed-Ali, Optics Communications 2018, 412, 134610140.

611 [50] U. Cvelbar, N. Krstulović, S. Milošević, M. Mozetič, Vacuum 2007, 82, 2.

612 [51] M. A. Razzak, K. Kondo, Y. Uesugi, N. Ohno, S. Takamura, J. Appl. Phys. 2004, 95, 2.

613 [52] J. Wang, Y. Du, X. Zhang, Z. Zheng, Y. Liu, L. Xu, P. Wang, J. Cao, Phys. Plasmas. $614 \mathbf{2 0 1 4}, 21,7$.

615 [53] X. Zhang, Z. Zhang, J. Cao, Y. Liu, P. Yu, AIP Advances 2018, 8, 3.

616 [54] T. Wegner, C. Küllig, J. Meichsner, Plasma Sources Sci. Technol. 2017, 26, 2.

617 